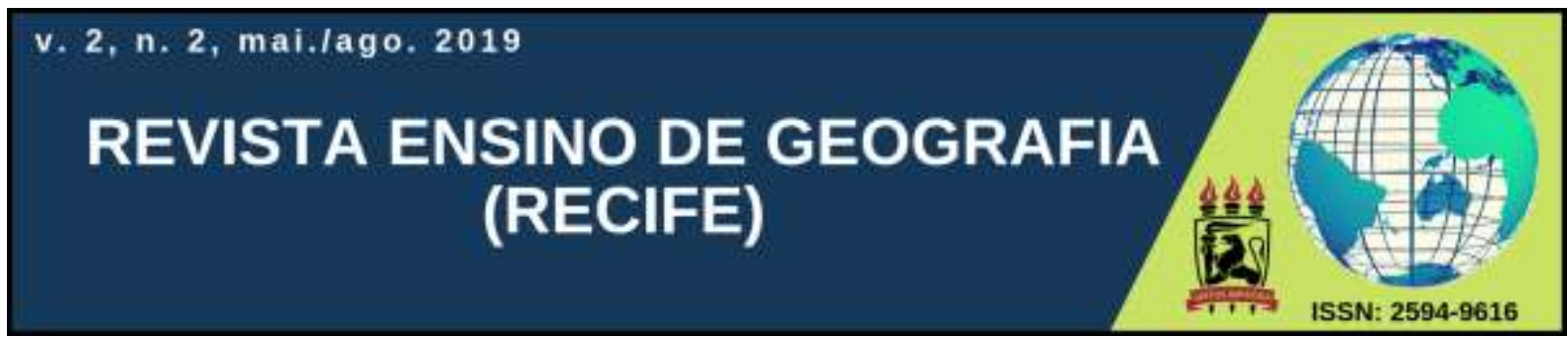

\title{
GEOGRAFIA ESCOLAR E CURRÍCULO: APORTES DA CONSTRUÇÃO DO SABER GEOGRÁFICO E DOS POSTULADOS ACADÊMICOS
}

\author{
Gilvan Charles Cerqueira de Araújo \\ Doutor pela universidade Estadual Paulista - UNESP \\ gcca99@gmail.com \\ ORCID Id: http://orcid.org/0000-0003-4238-0139 \\ Sidelmar Alves da Silva Kunz \\ Doutorando em Educação pela - UNB \\ sidel.gea@gmail.com \\ ORCID Id: http://orcid.org/0000-0002-0793-1946
}

Artigo recebido em 04/08/2019 e aceito em 03/12/2019

\begin{abstract}
RESUMO
Neste trabalho apresentamos a construção do saber geográfico tendo como prerrogativa as orientações didáticopedagógicas da Base Nacional Comum Curricular - BNCC. Por meio dos princípios norteadores do raciocínio geográfico é possível construirmos caminhos para uma base conceitual e categorial do pensamento geográfico em sua ponte com a Geografia Escolar, buscando o aperfeiçoamento e aprofundamento da base epistemológica da Geografia para a prática cotidiana em sala de aula e construção de novas possibilidades curriculares, fortalecidas pelo resgate do escopo teórico e metodológico da Geografia. Sendo assim, o objetivo principal do trabalho é propor uma dialogia entre as produções e reflexões acadêmicas, voltadas e referentes à Geografia Escolar, com a construção de novas vias curriculares para esta ciência. Por meio dos elementos constituintes do cerne da chegada dos postulados epistemológicos da Geografia na escola, vislumbra-se como foco no debate a apresentação de caminhos para construção curricular para a Geografia no ambiente escolar.
\end{abstract}

Palavras-chave: Geografia Escolar, Currículo, Epistemologia da Geografia, Raciocínio Geográfico.

\section{SCHOOL GEOGRAPHY AND CURRICULUM: CONTRIBUITONS FOR A CONSTRUCTION'S GEOGRAPHICAL KNOWLEDGE AND ACADEMIC POSTULES}

\section{ABSTRACT}

In this paper we present the construction of geographical knowledge based on the didactic-pedagogical orientations from the Common National Curriculum Base - BNCC from Brazil. Through the guiding principles of geographical reasoning it is possible to build paths for a conceptual and categorical basis of geographic thinking in its relationship with School Geography, searching to improve and deepen the epistemological fundamentals references of the Geography for everyday classroom practice and construction of new curriculum possibilities, strengthened by the rescue of the theoretical and methodological scope of Geography. Therefore, the main objective of the work is to propose a dialogue between the academic productions and reflections, focused and referring to School Geography, with the construction of new curricular pathways for this academic science. Through the constituent elements of the core of the arrival of the epistemological postulates of Geography in school, the focus of the debate is on the presentation of paths for curricular construction for Geography in the school environment.

Keywords: School Geography, Curriculum, Epistemology of Geography, Geographic Reasoning. 


\section{INTRODUÇÃO}

O trabalho faz uma abordagem das conexões entre os conceitos e pensamentos das diferentes geografias com os saberes e conteúdos presentes e exigidos na Geografia escolar. E, neste horizonte, assume como objetivo abordar os aportes da construção do saber geográfico e dos postulados acadêmicos que podem subsidiar na elaboração do currículo de geografia escolar.

Desta maneira, perfilam-se diferentes capacidades a serem obtidas, desenvolvidas e aperfeiçoadas, para que o ensinar a Geografia se concretize com êxito. Correntes pedagógicas, paradigmas de pensamento, correlações categoriais e conceituais, identificação de movimentações, paralelismos, afastamentos e aproximações discursivos fazem parte deste caminho de aprendizagem a ser trilhado na busca do aprimoramento do ensinar Geografia.

Dentre estas habilidades e instrumental teórico metodológico do ensino e aprendizagem da ciência geográfica podemos destacar a capacidade de conhecer e reconhecer as diferentes correntes e ideologias geográficas e como suas visões a respeito desta ciência foram transpostas para o ensino da Geografia.

Nessa proposta também será possível enriquecer a formação dos docentes no sentido de obter maiores conhecimentos teóricos, metodológicos e epistemológicos a respeito de sua área de formação, e como repassar tais conhecimentos aos desafios do ensino e aprendizagem escolares. $\mathrm{E}$, este movimento de retomada e resgate dos embasamentos formativos dos procedimentos de ensino e aprendizagem são fundamentais neste artigo.

A história da Geografia é marcada por diferentes correntes de pensamento dessa ciência, provindas das matrizes paradigmáticas integrantes desse conhecimento científico. Quando pensamos na prática docente, no cotidiano escolar, há infiltrações destas ideologias, correntes de pensamento e matrizes paradigmáticas, por meio da escolha e direcionamento da atividade pedagógica do professor de Geografia.

Desta maneira, é necessário que os professores se apropriem da prática investigativa e de pesquisa, para sua formação própria e para sua atividade docente diária:

Se considerarmos a docência como atividade intelectual e prática, revela-se necessário ao professor ter cada vez maior intimidade com o processo investigativo, uma vez que os conteúdos, com os quais ele trabalha, são construções teóricas fundamentadas na pesquisa científica. (PONTUSCHKA; PAGANELLI; CACETE, 2007, p. 95-96). 
Em face disso, se requer do professor um olhar para si como estudioso de sua própria área de formação, isto é, esforçar-se para construir uma epistemologia do ensino do seu campo de saber.

\section{CONTEXTUALIZAÇÃO}

Conseguiremos chegar a uma compreensão melhor fundada da Geografia escolar ao elencar e compreender os meandros historiográficos, alguns dos principais suportes e fundamentos epistemológicos e as conexões destas fundamentações com as tendências pedagógicas vigentes e pretéritas. A presença de um documento norteador para a orientação curricular nacional, como é o caso da BNCC, nos coloca diante de um campo de possibilidades de reflexão e prática didáticoescolar, mais do que uma periculosidade do documento diante de nossas redes de ensino, como argumenta Girotto (2017).

O autor nos adverte que: "[...] diante do contexto político e econômico do Brasil e da América Latina, cabe-nos a luta pela garantia das condições efetivas da prática educativa." (GIROTTO, 2017, p. 438), mas ao mesmo tempo é preciso que sejamos propositivos, construtivos e que busquemos aberturas e caminhos dentro dos normativos nacionais para os professores e estudantes, sujeitos protagonistas do processo de ensino e aprendizagem.

Esta observação quanto ao papel da BNCC, como referência de construção curricular nacional e a organização sintética do pensamento geográfico é o que apresentamos neste trabalho, para assim chegarmos à discussão sobre o ensino, a aprendizagem e as propostas curriculares para a Geografia. As ciências possuem seus desdobramentos discursivos, de pensamento e desenvolvimento de seus referenciais teóricos e metodológicos.

Com a Geografia não seria diferente, e é de fundamental importância que os profissionais da educação que atuam com a formação geográfica, básica ou superior, apropriem-se deste escopo epistemológico, de maneira que o mesmo sirva como aporte instrumental e de reflexão em sua prática docente. Em um âmbito social, geográfico e econômico tão diversificado e multifacetado, é importante que tenhamos propostas de orientação curricular para as redes de ensino, com prescrições essenciais para as aprendizagens.

Nesse contexto, a base conceitual e categorial da Geografia permite que o acadêmico desta área do conhecimento construa uma sólida fundamentação de sua ciência. Ter conhecimento da diversidade de conceitos, dos princípios lógicos, dos encontros e desencontros da historiografia científica e filosófica que permeiam a ciência geográfica vem ao encontro desta retomada do aperfeiçoamento formativo tão caro aos profissionais da educação. 
Somente a partir do momento em que estes alicerces conceituais e históricos estiverem bem dispostos é que poderemos refletir sobre uma epistemologia do ensino geográfico ou da Geografia escolar. Nesse sentido, estamos voltados e atentos para o panorama pretérito e contemporâneo da ciência geográfica. Isso é sumário para o diálogo constante e necessário também com a formação didático-pedagógica, formando uma rede de conexões, composições e justaposições essenciais para o entendimento da formação discente e docente em Geografia.

\section{O SABER GEOGRÁFICO: CATEGORIAS, CONCEITOS E TEMAS DA GEOGRAFIA}

A Geografia, assim como outras ciências, possui um escopo epistemológico, a partir do qual seu discurso, método, metodologias, práticas e correntes de pensamento se desmembram em múltiplas aplicações de conceitos, em análises ou sínteses da natureza e sociedade.

Esta aparente dualidade de áreas do pensamento geográfico o acompanha e coloca em constante debate, especialmente quando pensamos nas grandes especializações que a Geografia vem passando nas últimas décadas, favorecendo muito mais uma cisão e afastamento que uma aproximação e diálogo entre as denominadas Geografias Física e Humana.

No entanto, independente do curso de desenvolvimento teórico trilhado pelas múltiplas geografias que conhecemos, uma coisa permanece: a presença da premissa categorial da espacialidade. Temos, então, o espaço como categoria primeira e basilar do pensamento geográfico e, a partir desta, o desmembramento conceitual tão caro à Geografia por meio do lugar, território, paisagem e região. Vejamos, a seguir, um breve aprofundamento a respeito de cada um destes conceitos advindos da categoria espaço, fundamento epistemológico primário da Geografia.

Pontua-se que a categoria diz respeito à agregação de sentidos múltiplos que um objeto ou fenômeno podem receber, seja em sua concretude ou abstração. Uma categoria, desta forma, reverte em si a complexidade de diversas possibilidades de desdobramento e aplicações de pensamento e método. Os conceitos são desmembramentos categoriais, assim como os princípios lógicos. Toda ciência possui tanto categorias primárias como miríades de princípios e conceitos que compõem o seu escopo epistemológico. E, tanto a categoria como os conceitos e princípios possuem diferentes modulações espaciais e temporais, pois representam os contextos de suas concepções e usos, refletindo a sociedade e os discursos científicos em que estão inseridos.

Podemos organizar a epistemologia do pensamento geográfico com base em uma categoria primária e fundamental, que é o espaço, e seus conceitos-chave, desmembrados desta referência categorial, que são o território, o lugar, a paisagem e a região. Vejamos no Quadro 1, separadamente, as principais características de cada um destes referenciais epistemológicos e 
metodológicos do pensamento geográfico (CALLAI, 1995; CASTELLAR, 2005; PONTUSCKHA

et al., 2007).

\section{Quadro 1: Referenciais epistemológicos e metodológicos do pensamento geográfico}

\begin{tabular}{|c|c|}
\hline Referenciais & Principais características \\
\hline Espaço & $\begin{array}{l}\text { O espaço pode ser considerado a categoria maior do pensamento geográfico. Por agregar em si } \\
\text { todos os demais conceitos e princípios da Geografia o espaço assume um protagonismo teórico } \\
\text { ímpar. Quando pensamos em quaisquer referenciais geográficos sempre haverá, de forma } \\
\text { inerente, a presença da espacialidade, já que há uma ligação direta da ciência geográfica com } \\
\text { seu objeto de estudo, que é o espaço, seja na elaboração de metodologias de análises ou na } \\
\text { composição de discursos epistemológicos em diferentes correntes de pensamento, ideologias de } \\
\text { escolas geográficas e nas matrizes paradigmáticas presentes no processo de desenvolvimento da } \\
\text { própria Geografia. O espaço, portanto, seja aquele mais próximo dos aspectos naturais e físicos, } \\
\text { ou mais conectado com as características culturais e históricas, contém e fundamenta todo o } \\
\text { escopo teórico e metodológico do pensamento geográfico. }\end{array}$ \\
\hline Território & $\begin{array}{l}\text { Este conceito está ligado a dois pontos ora distintos ora complementares. De um lado há as } \\
\text { relações de poder que podem ser encontradas e estudadas no espaço geográfico. O controle, } \\
\text { domínio, disputas, encontros e choques dos interesses e poderes na espacialidade definem o } \\
\text { território, em estabelecimento de fronteiras, expansão ou retração de limites espaciais, } \\
\text { estabelecimento de referenciais de apoderamento ao local em que se vive, em detrimento de } \\
\text { outro grupo que ali também pode viver, etc. O outro aspecto ligado ao conceito-chave } \\
\text { geográfico território é sua proximidade com a ideia de lugar, quando a identidade e o sentido do } \\
\text { habitar faz parte da totalidade da presença humana numa determinada espacialidade, sendo } \\
\text { utilizado, inclusive, a denominação de "territorialidade" para esta característica identitária } \\
\text { comum, por exemplo, em histórias de formação territorial de diferentes povos e nações. }\end{array}$ \\
\hline Lugar & $\begin{array}{l}\text { O conceito-chave mais ligado à questão da identidade, sendo muito explorado na corrente } \\
\text { geográfica de pensamento conhecida como Geografia Cultural ou Humanista. Além desta } \\
\text { relação com o a significação do espaço o lugar obteve importante protagonismo conceitual na } \\
\text { vertente mais crítica do pensamento geográfico contemporâneo, pelo fato de poder ser utilizado } \\
\text { como pêndulo escalar ao movimento de globalização e os fluxos produtivos do mercado } \\
\text { mundial. O local e o global, desta forma, receberam (e ainda recebem) atenção em tais linhas de } \\
\text { estudos geográficos, assim como a questão do lugar mais próximo da ligação afetiva e } \\
\text { simbólica com o espaço, também com grande perenidade científica em discursos, teorias e } \\
\text { metodologias geográficas. }\end{array}$ \\
\hline Paise & $\begin{array}{l}\text { Este conceito-chave da Geografia possui sua importância para esta ciência desde o surgimento } \\
\text { da mesma. Sua ideação aproxima-se de um recorte imagético do meio, compondo-o em seus } \\
\text { diferentes elementos, em sobreposição, justaposição ou mesclagem, originando as diversas } \\
\text { paisagens que conhecemos. Antes de se configurar como um campo científico estabelecido era a } \\
\text { paisagem que congregava os estudos geográficos, normalmente aproximando mais de uma } \\
\text { abordagem mais descritiva e não analítica - elencando os elementos, tanto naturais como sociais } \\
\text { do espaço. Durante a passagem das décadas, a partir do início do século XX, a paisagem } \\
\text { recebeu maior protagonismo, inicialmente no possibilismo francês e, posteriormente, ganhando } \\
\text { notoriedade na Geografia Cultural, em novas interpretações e aplicações deste conceito em } \\
\text { diferentes morfologias da paisagem. }\end{array}$ \\
\hline Região & $\begin{array}{l}\text { A região, assim como os demais conceitos-chave da Geografia, perpassou por diferentes } \\
\text { correntes geográficas de pensamento. De modo geral a região é o conceito que podemos } \\
\text { estabelecer limites epistemológicos mais claros, já que sua complexidade se dá pela } \\
\text { diferenciação entre a região e regionalização. Desta forma, a região é já o recorte espacial } \\
\text { estabelecido, de acordo com algum critério específico, elegido como tal a partir do interesse } \\
\text { econômico, político, científico, cultural a que se deseja dividir determinada porção do espaço. } \\
\text { Do outro lado há a regionalização, que é, sempre, um processo, um movimento contínuo de } \\
\text { busca pela melhor divisão do espaço para se chegar a uma integração mais aprimorada da sua } \\
\text { diversidade como ocorre, por exemplo, nas diferentes propostas regionais de países, estados e } \\
\text { cidades, que precisam passar constantemente por atualizações. }\end{array}$ \\
\hline
\end{tabular}

Elaboração própria. 
Percebam que há grandes diferenciações entre os conceitos-chave do pensamento geográfico e de como o espaço, como categoria mestra da Geografia perpassa todos eles, assim como nos princípios do raciocínio geográfico. Os princípios e postulados geográficos também podem ser localizados nestes referenciais teóricos como a circulação, os fluxos, os objetos espaciais, a dinâmica de produção e uso de recursos, dentre outros.

A partir da apropriação deste instrumental teórico o professor agrega valor pedagógico à sua prática docente, ao mesmo tempo em que se coloca o desafio de levar toda esta riqueza e espessura conceitual para o ambiente escolar. A Geografia escolar precisa se pautar no referencial base de sua ciência de origem, um caminho a ser trilhado pelos profissionais da educação geográfica.

Em concordância e concomitância com esta exigência da apropriação epistemológica por parte dos professores é que a BNCC de Geografia elenca alguns princípios do raciocínio geográfico, todos relacionados tanto com a espacialidade categorial como seus desdobramentos conceituais, ressaltando ainda mais o papel de oferecer alternativas à prática pedagógica cotidiana com o fundamento teórico da ciência geográfica, conforme podemos observar no Quadro 2.

Quadro 2: Princípios do Raciocínio Geográfico

\begin{tabular}{|c|c|}
\hline Princípio & Descrição \\
\hline Analogia & $\begin{array}{l}\text { Um fenômeno geográfico sempre é comparável a outros. A identificação das semelhanças entre } \\
\text { fenômenos geográficos é o início da compreensão da unidade terrestre. }\end{array}$ \\
\hline Conexão & $\begin{array}{l}\text { Um fenômeno geográfico nunca acontece isoladamente, mas sempre em interação com outros } \\
\text { fenômenos próximos ou distantes. }\end{array}$ \\
\hline Diferenciação & $\begin{array}{l}\text { É a variação dos fenômenos de interesse da geografia pela superfície terrestre (por exemplo, o } \\
\text { clima), resultando na diferença entre áreas. }\end{array}$ \\
\hline Distribuição & Exprime como os objetos se repartem pelo espaço. \\
\hline Extensão & Espaço finito e contínuo delimitado pela ocorrência do fenômeno geográfico. \\
\hline Localização & $\begin{array}{l}\text { Posição particular de um objeto na superfície terrestre. A localização pode ser absoluta (definida por } \\
\text { um sistema de coordenadas geográficas) ou relativa (expressa por meio de relações espaciais } \\
\text { topológicas ou por interações espaciais). }\end{array}$ \\
\hline Ordem & $\begin{array}{l}\text { Ordem ou arranjo espacial é o princípio geográfico de maior complexidade. Refere-se ao modo de } \\
\text { estruturação do espaço de acordo com as regras da própria sociedade que o produziu. }\end{array}$ \\
\hline
\end{tabular}

Fonte: BNCC (BRASIL, 2017, p. 358).

Cada um destes princípios apresentados no Quadro 2 dialoga entre si e com a espacialidade categorial do pensamento geográfico além, é claro, de trazerem consigo diferentes possibilidades de análise e síntese dos conceitos e temas da Geografia. Princípios como extensão e circulação, por exemplo, são facilmente passíveis de uso em campos da Geografia em relação com economia ou ocupação do espaço, de modo a correlacionar o movimento de mercadorias e pessoas no 
território. Aplicados à realidade escolar, permitem que o estudante adquira um instrumental de compreensão das transformações naturais e sociais da realidade que o cerca:

\begin{abstract}
Alguns princípios precisam ser discutidos se quisermos que o professor se constitua em pesquisador: domínio do conhecimento geográfico a ser ensinado e dos caminhos teóricometodológicos existentes para trabalhar sua disciplina e a necessidade da colaboração das diferentes disciplinas para a compreensão da complexidade do mundo" (PONTUSCHKA; PAGANELLI; CACETE, 2007, p. 26).
\end{abstract}

Ressaltamos a importância da apropriação epistemológica pelos professores do Ensino Básico: A formação de professores deve se pautar na apropriação das bases históricas, teóricas e metodológicas de sua ciência formativa. Esta é uma condição mister para que tenhamos cada vez mais clareza na hora de propor currículos e pensar sobre a didática, o ensino e as aprendizagens das diferentes ciências e saberes.

A Geografia possui grande fragmentação das explanações do seu objeto de estudo, ao mesmo tempo que traz consigo a riqueza de múltiplas possibilidades de representação do saber geográfico:

No afã de descrever os lugares a Geografia na sala de aula é uma geografia que fragmenta a realidade, privilegia o natural em detrimento do humano e apresenta o espaço como algo produzido por forças naturais, sem incorporar o homem (a sociedade), o aluno como um ser que tem história, que tem uma trajetória de vida (desde a sua família), e que constrói neste processo um (o seu espaço). (CALLAI, 1995 p. 43)

Os saberes e conhecimentos da academia precisam chegar às salas de aula. Esta "tradução" será feita pelos professores das diferentes áreas. No caso da Geografia o instrumental teórico do professor se coloca como ponto fundamental para realização deste processo:

O conhecimento produzido na universidade, fundamentado em pesquisas de campo de laboratório e de bibliografia e dominado pelo professor, deve constituir instrumental teórico a ser elaborado, recriado, para transformar-se em saber escolar, ou seja, em saber a ser ensinado." (PONTUSCHKA; PAGANELLI; CACETE, 2007, p. 26-27).

E neste sentido de construção do instrumental teórico e metodológico que o fundamentará na sua prática cotidiana, o professor pode fazer uso dos pressupostos da $\mathrm{BNCC}$, em relação ao ensino de Geografia.

Envolto nesta premissa temos também de considerar as contradição da BNCC, como já mencionado no estudo de Girotto (2017), rem relação a padronização do trabalho docente na perspectiva de um currículo nacional, o que não nos impede de pensarmos no fortalecimento 
epistemológico destes professores nas salas de aula, a partir dos pressupostos teóricos, especialmente do raciocínio geográfico, para a Educação Básica na Geografia Escolar.

\title{
POR UMA EPISTEMOLOGIA DO ENSINO
}

A formação inicial e continuada devem estar conectadas, se complementarem, como um processo contínuo de aperfeiçoamento dos profissionais da educação, que precisam acompanhar as transformações dos sujeitos da sociedade em que vivemos e transformamos, que demandam esta constante atualização de suas formações:

\begin{abstract}
Assim, sua prática pedagógica requer de si reflexão, crítica e constante criação e recriação do conhecimento e das metodologias de ensino, o que pressupõe uma atividade de investigação permanente que necessita ser apreendia e valorizada.[...] Nesse sentido, é importante que os professores, em seu processo formativo, sobretudo inicial, pesquisem como são produzidos os conhecimentos por eles ensinados (PONTUSCHKA; PAGANELLI; CACETE, 2007, p. 95-96).
\end{abstract}

Esclarece-se que é comum encontrarmos, nos materiais de formação docente e de iniciação a graduação em geral, referências tanto à Epistemologia como à Filosofia da Ciência. A principal diferença de ambas é que, no primeiro caso, estamos nos referindo aos meta-estudos científicos, ou seja, é a ciência estudando ela mesma, seus métodos, teorias e conceitos. No segundo caso, temos uma proximidade maior com a filosofia, a produção do conhecimento, na ciência como um todo ou em áreas específicas, a depender do interesse do filósofo que escreve a obra em questão.

As ciências propõem explicações para a realidade, a sociedade e a natureza, o mundo e o sujeito. A Geografia insere-se neste contexto em matrizes paradigmáticas e correntes de pensamento. Desta maneira, utilizemos como referência das tendências pedagógicas de Luckesi (1991) para que possamos relacioná-los com a proposta de uma epistemologia do ensino geográfico:

Conhecimento significa uma forma de entendimento da realidade, ou seja, uma forma de compreensão de alguma coisa, tanto no seu modo de ser quanto no seu modo de operar com ela. O conhecimento não é apenas uma forma de obter e reter informações. É muito mais que isso. E uma forma de entender a realidade como ela é e no seu funcionamento, a partir dos múltiplos elementos que a explicam. [...] Conhecimento é, portanto, um instrumento de vivência e sobrevivência. Não significa apenas uma "ilustração da mente" (LUCKESI, 2011, p. 110) 
A escola, como instância educativa, tem por papel a elevação cultural dos seus educandos. Ela é uma instância importante e significativa da sociedade (LUCKESI, 2011, p. 110). A epistemologia do ensino de Geografia deve voltar-se para esta dialogia entre as tendências pedagógicas e os temas e teorias da ciência geográfica, permitindo ao estudante encontrar-se como sujeito na elaboração e compreensão deste conhecimento em sua prática social: "A cultura elaborada é um elemento que obriga a uma ruptura com a situação cultural anterior do indivíduo, possibilitando-lhe "ser outro" (LUCKESI, 2011, p. 110).

Em concordância com Luckesi (2011), podemos relacionar as considerações de Castellar (2005), que vão ao encontro destas reflexões do autor - sobre a cultura elaborada no ambiente escolar - sobre a aprendizagem da Geografia na Educação Básica:

Assim, toda a aprendizagem da geografia na educação básica, entendida como um processo de construção da espacialidade que corresponde a orientar-se, deslocar-se no espaço, pode ser associada aos seguintes objetivos:

1) Capacitar para a aplicação dos saberes geográficos nos trabalhos relativos a outras competências e, em particular, capacitar para a utilização de mapas e métodos de trabalho de campo.

2) Aumentar o conhecimento e a compreensão dos espaços nos contextos locais, regionais, nacionais, internacionais e mundiais e, em particular:

- conhecimento do espaço territorial;

- compreensão dos traços característicos que dão a um lugar a sua identidade;

- compreensão das semelhanças e diferenças entre os lugares;

-compreensão das relações entre diferentes temas e problemas de localizações particulares;

- compreensão dos domínios que caracterizam o meio físico e a maneira como os lugares foram sendo organizados socialmente; (CASTELLAR, 2005, p. 2011).

Após termos trabalhado com a ideia de uma epistemologia do ensino geográfico ou da Geografia escolar, podemos partir, agora, em direção ao diálogo, necessário e constante, das teorias e métodos da pedagogia com o arcabouço conceitual e metodológico da Geografia, tanto com os conceitos-chave da Geografia como, também, nas correntes de pensamento clássicas e direcionamentos contemporâneos da Geografia como um todo e a Geografia Escolar, particularmente.

Este é um desafio não apenas da ciência geográfica, mas de todo componente curricular, quando este passara do ambiente restritamente acadêmico para a realidade escolar:

Um dos grandes desafios dos cursos de formação de professores de geografia diz respeito à necessidade prática de articulação dos conteúdos desse componente curricular com os conteúdos pedagógicos e educacionais, ou seja, aos mecanismos de transposição didática, que envolvem metodologias do ensinar a ensinar (PONTUSCHKA; PAGANELLI; CACETE, 2007, p. 99). 
A Geografia escolar, portanto, enquadra-se nesta concepção de prática social pedagógica, e deve pautar seus esforços no sentido de atentar e justificar sua importância, de forma ininterrupta, a cada novo conceito, avaliação, tema ou atividade proposta. Vejamos no Quadro 3 quais seriam os principais métodos geográficos que podem ser direcionados para o ensino de Geografia no âmbito da Educação Básica.

Quadro 3: Métodos geográficos aplicáveis no ensino de Geografia na Educação Básica

Utilização, com maior frequência das tecnologias da informação e comunicação (TICs) na sala de aula, principalmente colocando em pauta os recursos interacionais multimídias da geração atual com as propostas curriculares vigentes.

Contextualização dos conteúdos e temas com a situação histórica e geográfica contemporânea, com vistas a fortalecer a interligação do que é aprendido na sala de aula com as experiências de vida ocorridas fora desta.

Dialogia contínua com as áreas correlatadas da Geografia e com demais campos do saber, com o objetivo de criar pontes temáticas, por trans, inter e multidisciplinaridade nos conteúdos, habilidades e competências exigidos em cada etapa do percurso escolar.

Diversificação e enriquecimento das estratégias de avaliação, de modo a propiciar aos estudantes diferentes formas de demonstrar seus aprendizados e compreensões a respeito do que está sendo estudado.

Utilização do recurso de maior participação e protagonismo estudantil na sala de aula com, por exemplo, a adoção de metodologias ativas de produção de saberes a partir do que está sendo aprendido sobre os postulados científicos na escola.

Entendimento e adaptação do que há de mais recente nos estudos acadêmicos para a atualização dos conteúdos e competências curriculares, em diferentes áreas. No caso da Geografia esta premissa aplica-se tanto aos estudos ambientais e naturais quanto aos voltados para a cultura e sociedade.

Elaboração própria.

Como vimos anteriormente, o conhecimento acompanha as mudanças da sociedade, alterase, retrai ou avança, de acordo com um conjunto inumerável de fatores. No caso da Geografia, por possuir o espaço como categoria central, precisa de constante acurácia epistemológica para acompanhar as mudanças da realidade, em sua esfera natural e social.

Aproximar-se do lastro didático-pedagógico não é uma alternativa, e sim uma condição primária, sem a qual não apenas a Geografia escolar, mas quaisquer outros campos do saber não alcançarão seus objetivos de tornar inteligíveis seus paradigmas, correntes de pensamento, métodos de análises, hipóteses e visões de mundo.

Geografia, assim como outros campos do saber, precisa atentar-se, sempre, para as mudanças do mundo contemporâneo, em que pese as orientações normativas de orientação para referenciais curriculares nacionais, como é o caso da BNCC. A diversidade social, local e regional deve também fazer parte dos percursos de ensino e aprendizagem, especialmente no que se refere ao ensino de Geografia (GIROTTO, 2017).

Acompanhar uma nova movimentação política, uma alteração climatológica, um desastre natural, um programa de avaliação e critérios de análise demográfica governamental, alianças e 
decisões geopolíticas, etc. Como o espaço abrange o mundo, o objeto de estudo da Geografia torna-se tão mais dinâmico quanto maiores forem nossas formas de acompanhar estas mudanças.

Dar sentido ao saber, eis o maior desafio dos professores. A escola ocupa um lugar de singular notoriedade por agregar em seu ambiente as possibilidades imensuráveis de apresentar e propiciar aos estudantes os meios pelos quais compreenderão, questionarão e poderão compreender o seu papel - como sujeito e parte de uma coletividade no mundo que habita e transforma:

Estudar Geografia é uma oportunidade para compreender o mundo em que se vive, na medida em que esse componente curricular aborda as ações humanas construídas nas distintas sociedades existentes nas diversas regiões do planeta. Ao mesmo tempo, a educação geográfica contribui para a formação do conceito de identidade, expresso de diferentes formas: na compreensão perceptiva da paisagem, que ganha significado à medida que, ao observá-la, nota-se a vivência dos indivíduos e da coletividade; nas relações com os lugares vividos; nos costumes que resgatam a nossa memória social; na identidade cultural; e na consciência de que somos sujeitos da história, distintos uns dos outros e, por isso, convictos das nossas diferenças (BRASIL, 2018, p. 359).

Devemos nos perguntar, então, o que seria pensar pedagogicamente a Geografia no ambiente escolar, e com base no que apresentamos até aqui acrescenta-se: "Pensar pedagogicamente os saberes geográficos numa perspectiva metodológica e significativa para os alunos implica desenvolver ações que reestruturem os conteúdos, inovem os procedimentos e estabeleçam com clareza os objetivos" (CASTELLAR, 2005, p. 220).

Figura 1: A Geografia escolar

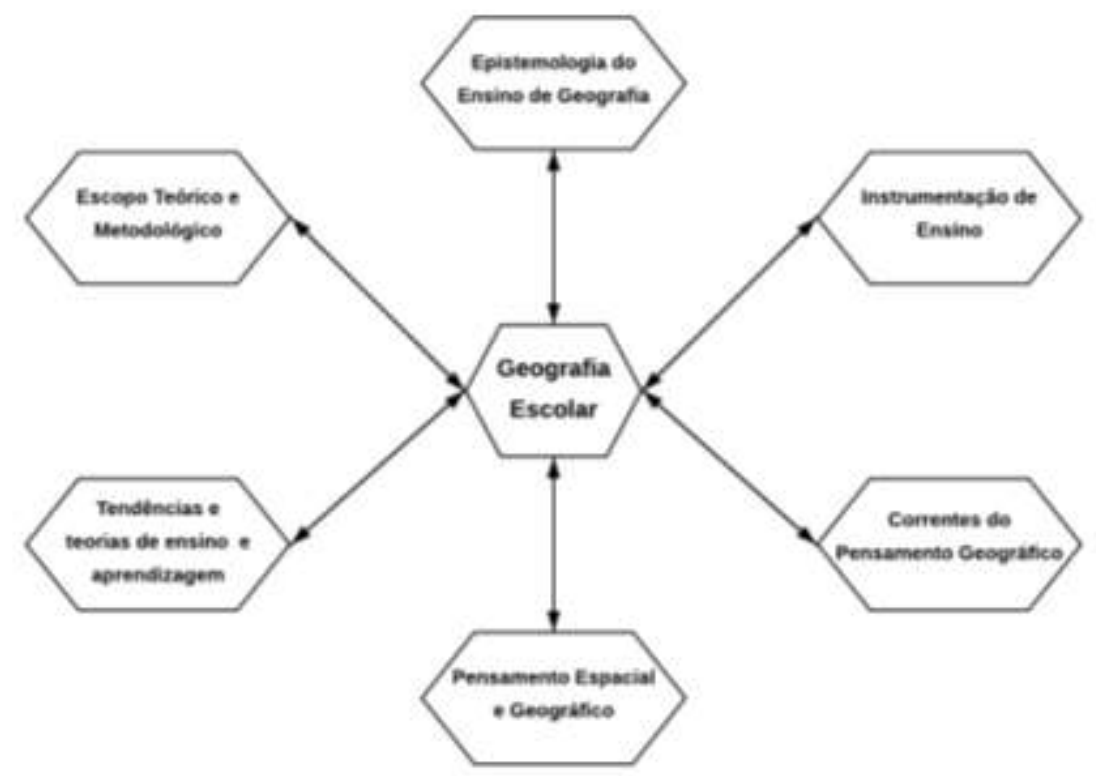

Fonte: Elaboração própria. 
A partir deste organograma apresentado na Figura 1, observamos que o pensamento espacial e geográfico, a instrumentação de ensino, as tendências e teorias de ensino e aprendizagem, o pensamento geográfico e espacial e as correntes de pensamento da Geografia bem como a epistemologia do Ensino da Geografia correlacionam-se, para formar a totalidade do que entendemos por Geografia escolar, em suas singularidades e complexidade em mútua interação.

É fundamental termos presente que a aprendizagem envolve compreensão, pois o que se aprende sem compreender não é verdadeiro. Estudar os nomes dos rios do Brasil ou da Rússia e os eixos viários que dão acesso às principais metrópoles do País somente será válido se for para a construção de significados, ou seja, se esses estudos tiverem significado na vida das pessoas e dos nossos alunos. (PONTUSCHKA; PAGANELLI; CACETE, 2007, p. 31).

Se não houver a compreensão do que está sendo apresentado então o conhecimento não atingirá seu alcance de significado, ou seja, estará esvaziado de sentido. Mesmo que haja todo esforço teórico, metodológico, procedimental e instrumental, bem como o referencial histórico e epistemológico por parte dos professores, se esta carga didático-pedagógica não se conectar aos estudantes, os saberes, conceitos, categorias e princípios apresentados perderão o seu potencial de aprendizagem, tornando-se apenas mais um aglomerado de compêndios enciclopédicos passageiros na vida escolar daquele sujeito.

A relação escalar parte/todo e sujeito/mundo é um dos pontos-chave para a Geografia escolar. Posicionar o estudante em si mesmo e na sociedade que este faz parte é uma das maneiras mais profícuas de se aproveitar o potencial dialógico e pedagógico da ciência geográfica. Para cada conteúdo apresentado, seja mais próximo dos estudos ambientais ou culturais, é importante fazer este exercício de correlação escalar, buscando significar o que está sendo ensino com a realidade proximal do estudante e com o mundo que este está inserido como sujeito.

A nova BNCC de Geografia tem com um dos seus pilares formativos o diálogo interdisciplinar como parte da busca por uma nova significação da aprendizagem. É um caminho que promove o desencadeamento de múltiplos desafios aos professores, que precisarão repensar suas fronteiras formativas, de modo a construírem pontes de diálogo que dêem conta da nova proposta curricular nacional.

Geografia escolar e Epistemologia do ensino de Geografia caminham juntas, é claro, mas de nada adiantará colocá-las em relevo se o conhecimento não obtiver significado aos estudantes. A escola deve ser o ambiente no qual todo o esforço de reflexão e prática educativa deve se voltar, 
mas não de maneira cerrada nos muros deste ambiente, pelo contrário, tendo como objetivo sempre conectar os sabres aprendidos na sala de aula com a realidade do outro lado, compreendendo o saber geográfico como algo unificado, em suas diferentes escalas de síntese, análise e aprendizagens.

\section{CONSIDERAÇÕES FINAIS}

Essa perspectiva elucidada nos assegura uma caminhada com clareza e maturidade para pensar essa ciência, seus meandros, efeitos e reflexos na vida em sociedade. $O$ ensino de geografia, nesse tocante, se apresenta como crucial para o desenvolvimento de ideias, posturas e compreensões tendo em vista a construção do futuro. Para tanto, é crucial a discussão do andamento das diretrizes de ensino dessa disciplina, o entendimento dos movimentos curriculares que, a rigor, expressam um quadro social em um dado tempo, a reflexão acerca da orientação filosófica que se situa como pano de fundo para determinadas escolhas e ênfases em determinado campo da ciência geográfica, dentre outros aspectos.

Com base nos pontos apresentados, ficou evidenciado a importância de se dominar os referenciais concernentes as distintas correntes de pensamento e os paradigmas da geografia que são postulados como matizes fundamentais para o fazer e o pensar geográfico.

Refletir epistemologicamente é ser capaz de compreender o porquê que um conteúdo tem a tendência de ser trabalhado de um modo e não de outro. Também coloca-se como desafio a iniciativa de desvendar o porquê de se trabalhar com esse conteúdo e não com outro, mas, ao mesmo tempo, conseguir perceber os movimentos teóricos e as suas consequências para os rumos da política, da economia e da cultura e qual é o grau de contribuição do ensino de geografia nessas dinâmicas de formação de um sujeito em seu papel na sociedade e mundo que faz parte.

Ao professor de Geografia, tanto da Educação Básica como do Ensino Superior, cabe ter com clareza as aproximações e distanciamentos das definições deste referencial teórico da Geografia. Princípios, categorias, conceitos, temas, conteúdos, fatos e fenômenos, conteúdos, habilidades e competências curriculares, todos entremeados pela sociedade e a natureza; todos estes pilares do pensamento geográfico possuem sua rota de chegada à sala de aula e à formação do professor de Geografia.

O passo inicial a ser dado é o da apropriação teórica e metodológica por parte dos professores de Geografia. Após esta consciência epistemológica de seu labor didático e pedagógico haverá diversas maneiras de se buscar formas para que o conhecimento que 
representa, o campo geográfico, possa ser apresentado aos seus alunos. Este é o desafio posto na chegada da ciência ao ambiente escolar.

\section{REFERÊNCIAS}

BRASIL. Base Nacional Comum Curricular: Educação Infantil e Ensino Fundamental. Brasília: MEC/Secretaria de Educação Básica, 2017.

CALLAI, Helena Copetti. Geografia: um certo espaço, uma certa aprendizagem. Tese de Doutorado. Universidade de São Paulo, 1995.

CASTELlAR, Sonia. Educação Geográfica: A psicogenética e o conhecimento escolar. Cad. Cedes, Campinas vol. 25 n.66 pg. 209-225 maio/agosto 2005. Disponível em: http://www.scielo.br/scielo.php?script=sci_arttext\&pid=S0101-

32622005000200005\&lng=pt\&tlng=pt Acesso em: 03 ago. 2019.

GIROTTO, Eduardo Donizeti. Dos PCNs à BNCC: o ensino de geografia sob o domínio neoliberal. In: GEO UERJ (2007), v. 1, p. 419-439, 2017. Disponível em: https://www.epublicacoes.uerj.br/index.php/geouerj/article/view/23781 Acesso em: 25 nov. 2019

LUCKESI, Cipriano. Fazer universidade: uma proposta metodológica. $6^{\text {a }}$ ed. São Paulo: Cortez, 1991.

LUCKESI, Cipriano. Filosofia da Educação. São Paulo: Cortez, 2011.

PONTUSCKHA, NidiaNacib.; PAGANELLI, Tomokolyda; CACETE, NúriaHanglei. Para Ensinar e Aprender Geografia. São Paulo: Ed. Cortez, 2007. 